\title{
ESTIMATING BACTERIAL POPULATION ON THE PHYLLOSPHERE BY SERIAL DILUTION PLATING AND LEAF IMPRINT METHODS
}

\author{
Ram Kailash P. Yadav ${ }^{1}$, Katerina Karamanoli ${ }^{2}$ and Despoina Vokou ${ }^{3}$ \\ ${ }^{1}$ Central Department of Botany, Tribhuvan University, Kirtipur, Kathmandu, Nepal \\ ${ }^{2}$ Laboratory of Agricultural Chemistry, School of Agriculture, Aristotle University, Gr-541 24 \\ Thessaloniki, Greece \\ ${ }^{3}$ Department of Ecology, School of Biology, Aristotle University, Gr-541 24 Thessaloniki, Greece \\ *E-mail: rkp.yadav@cdbtu.edu.np
}

\begin{abstract}
The plant phyllosphere constitute a habitat for variety of microorganisms; bacteria are the most common ones. In this study, we assessed the ability of serial dilution plating and leaf imprint methods to elucidate population abundance on the phyllosphere of eight plant species co-occurring in the same area in mediterranean ecosystem (northern Greece). The serial dilution plating method outweighed the leaf imprint method in determining the total epiphytic bacterial population and the estimates were significantly higher. However, the ability to detect presence of bacterial colony on leaf surface is higher for the leaf imprints, suggesting specific use of this method for practical purposes.
\end{abstract}

Key words: Phyllosphere, bacterial population, serial dilution plating, leaf imprint.

\section{INTRODUCTION}

Phyllosphere bacteria have agricultural and environmental importance as they can affect plant growth and can also suppress and stimulate the colonization and infection of tissues by plant pathogens (Lindow and Brandl 2003, Rasche et al. 2006). Bacterial populations on the phyllosphere are very diverse and vary in size both among and within species, and also over short time scales (Kinkel et al. 1995, Yadav et al. 2004, Lambais et al. 2006). Furthermore, interactions in the phyllosphere determine the extent to which human pathogens are able to colonize and survive on plant tissues, such as fresh salad, fruit and vegetable produce (Whipps et al. 2008, Berger et al. 2010).
Culture methods to enumerate bacterial population have revealed high numbers of bacterial strains inhabiting leaf surfaces. For instance, 37 genera and 78 species of bacteria were isolated from wheat and 20 genera from mango leaves (Legard et al. 1994, de Jager et al. 2001). Cultureindependent methods have shown that the phyllosphere bacterial communities are more diverse than previously detected (Yang et al. 2001). Studies involving leaf imprints have shown that bacteria do not occur in a uniform pattern across leaf surfaces (Weller and Saettler 1980, Leben 1988).

Inability to grow most bacteria in the laboratory and the difficulties associated with bacterial 
identification set limitations in the description of microbial communities (Torsvik et al. 2002). In recent times, therefore, characterization of microbial communities by culture dependent methods have been under much scrutiny and voices are being raised in favour of culture independent methods such as molecular methods (McCaig et al. 1999), and characterization of community level physiological profile (Garland et al. 2001, PrestonMafhan et al. 2002, Yadav et al. 2008). However, culture methods (e.g., serial dilution plating, liquid broth culture, leaf imprints, etc.) are still thought appropriate and being widely used to characterize microbial populations from different habitat (Ritz 2007). In the present study, we attempt to compare the ability of the two culture methods (serial dilution plating and leaf imprint) in characterizing the bacterial abundance on the phyllosphere.

\section{MATERIALS AND METHODS}

We studied eight plant species (woody and non-woody perennials) naturally occurring and coexisting in the same area in the Mediterranean ecosystem in Halkidiki (northern Greece). The woody species are the evergreen-sclerophyllous shrubs, Arbutus unedo L., Quercus coccifera L., Pistacia lentiscus L. and Myrtus communis L. and the seasonal dimorphic shrubs, Lavandula stoechas L. and Cistus incanus L. They are all common components of the mediterranean-type ecosystems of the country. The non-woody perennials are Calamintha nepeta (L.) Savi and Melissa officinalis L. Sampling was done in the morning and leaf samples were placed in sterile plastic bags, were transported to the laboratory in an icebox, and were analyzed within $24 \mathrm{~h}$. The serial dilution plating method (Lindow et al. 1978) was used. Each sample was weighed and immersed in $25 \mathrm{ml}$ sterile phosphate buffer (0.01 M, pH 7.3) supplemented with $0.1 \%$ bactopeptone, in a 100 $\mathrm{mL}$ Erlenmeyer flask. Flasks were sonicated in an ultrasonic cleaner for $10 \mathrm{~min}$. Portions $(100 \mu \mathrm{L})$ from the original wash and appropriate dilutions thereof prepared in $0.01 \mathrm{M}$ phosphate buffer $(\mathrm{pH}$ 7.3) were plated onto nutrient agar (NAG) medium, supplemented with $2.5 \%$ (v/v) glycerol, and amended with $30 \mu \mathrm{g} \mathrm{mL} \mathrm{m}^{-1}$ natamycin to prevent fungal contamination.

In order to estimate the bacterial population on the adaxial and abaxial leaf surfaces, leaf imprints were made on agar media prepared as in dilution plating method. An intact individual leaf was placed onto agar plate and was pressed with the smooth end of a sterile glass rod until a clear imprint of the entire leaf was obtained on the agar surface (Aneja 2003). Different leaves were used for imprinting the adaxial and abaxial surfaces to avoid disturbances in surface community distribution. After bacterial extraction, each leaf was used to measure its area with leaf area meter (Ejkelkamp, Agrisearch Equipment, Netherland).

Plates with serial dilution plating and leaf imprints were incubated at $24^{\circ} \mathrm{C}$ for $2-5$ days. Bacterial populations were enumerated from the plates and expressed as log CFU (colony forming units) per square centimeter of leaf area. The reason for transforming CFUs into log CFUs is described in Yadav et al. (2004). CFU on adaxial and abaxial leaf surfaces were added to represent the bacterial population on leaf surface by imprint method. In case of dilution plating, leaf weights for each species were translated into leaf area (adaxial and abaxial) using leaf weight-leaf area relationship (linear regression model) with 30 samples. The highest degree of relationship was found in Myrtus communis $\left(R^{2}=0.986, p<\right.$ 0.0001 ) and the lowest was found in Quercus coccifera $\left(R^{2}=0.739, p<0.0001\right)$. Comparison of bacterial population estimates were done with oneway ANOVA and t-test by using SPSS for Windows (11.0.1, SPSS Inc., USA). 


\section{RESULTS AND DISCUSSION}

The size of bacterial population on the phyllosphere of eight species estimated by serial dilution plating and leaf imprint methods is presented in Fig. 1. There was significant variation $(p<0.0001)$ in population size between the groups and within the groups (Table 1). The average epiphytic bacterial population on the phyllosphere

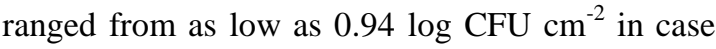
of $Q$. coccifera to as high as $3.92 \log \mathrm{CFU} \mathrm{cm} \mathrm{cm}^{-2}$ in $C$. nepeta as estimated by the serial dilution plating method. Results of leaf imprint method showed the highest population on the leaves of $C$. incanus

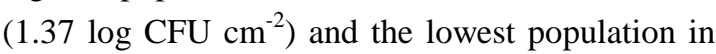
case of $A$. unedo (0.59 $\log \mathrm{CFU} \mathrm{\textrm {cm } ^ { - 2 }}$ ). Overall, $A$. unedo and $Q$. coccifera (evergreen sclerophyllous) are the least populated species based on either of the population estimation methods, while $C$. incanus (seasonal dimorphic), $C$. nepeta and $M$. officinalis (non-woody perennials and aromatic) were the most populated. This pattern is consistent with the population pattern found in these species over seasons (Yadav et al. 2004, 2005).

In this study, greater variation in population size in $C$. incanus, $C$. nepeta and M. officinalis determined by both methods can be attributed to the hairy and rough leaf surfaces they bear (Yadav et al. 2004a). However, leaf imprint method appeared as better one in terms of extent of detection of microbes on the leaf surface is concerned. This was evident by the fact that only one out of forty eight leaf samples had no detectable bacteria against nine in as many samples estimated by serial dilution plating method.

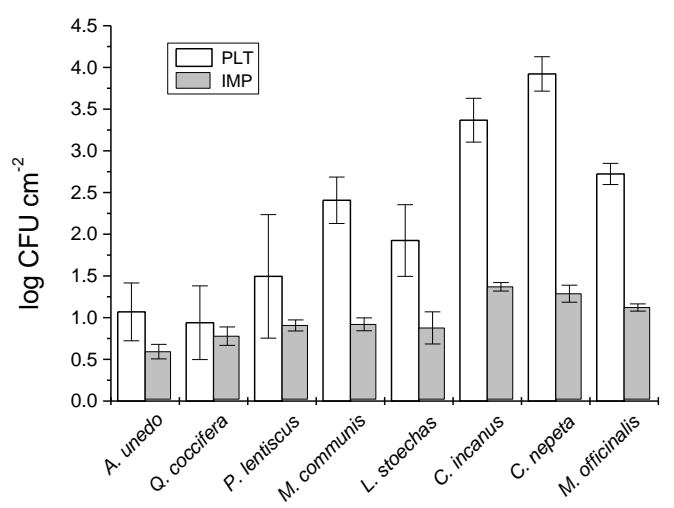

Fig. 1. Bacterial population of the phyllosphere of mediterranean species estimated by serial dilution plating method (PLT) and leaf imprint method (IMP). Bars represent mean values of

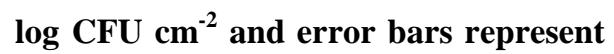
standard errors of the means $(n=6)$.

Table 1. Comparison of bacterial populations estimated by plate dilution (PLT) and leaf imprint (IMP) methods using one-way ANOVA.

\begin{tabular}{llccccc}
\hline Variables & & Sum of squares & d.f. & Mean square & F-value & Sig. \\
\hline PLT & Between groups & 48.46 & 7 & 6.92 & 7.37 & 0.000 \\
& Within groups & 37.60 & 40 & 0.94 & & \\
& Total & 86.07 & 47 & & & \\
& Between groups & 2.86 & 7 & 0.41 & 6.624 & 0.000 \\
& Within groups & 2.47 & 40 & 0.06 & & \\
& Total & 5.32 & 47 & & & \\
\hline
\end{tabular}


Table 2. Comparison of phyllosphere bacterial populations in all species estimated by serial dilution plating (PLT) and leaf imprint (IMP) methods.

\begin{tabular}{lll}
\hline Methods & $\log$ CFU cm $^{-2}$ & t-test \\
\hline PLT & $2.23 \pm 0.19(\mathrm{n}=48)$ & $\mathrm{t}=7.09$ \\
IMP & $0.98 \pm 0.05(\mathrm{n}=48)$ & $p<0.0001$ \\
\hline
\end{tabular}

In case of pair wise comparisons of two methods, bacterial population size varied significantly in most of the species (Fig. 1). The estimate by dilution plating outweighed that by the leaf imprint. When population data of all eight species were pooled for each method and compared (Table 2), the estimate by serial dilution plating method was found significantly higher $(p<$ 0.0001). The leaf imprint method underestimated the size of population of epiphytic bacteria compared to the dilution plating method, as has also been reported by other researchers (Jacques et al. 1995). Furthermore, the common sites of bacterial colonization on leaf surface are base of trichomes, stomata, cell wall junctions, vein endings and even beneath the cuticles (Mansvelt and Hattings 1987, Mariano and McCarter 1993, Knief et al. 2010). It is apparent that bacterial colonies in such sites are less likely to be recovered in a leaf imprint made on the nutrient agar. Leaf washings, on the other hand, can possibly remove cells from the colonies situated even under cuticle through pores and cracks (Corpe and Rheem 1989).

In conclusion, it is obvious that serial dilution plating is better than leaf imprint method regarding characterization of microbial abundance on the phyllosphere. Leaf imprint method only presents an underestimate of the population size but its ability to detect bacterial colony on leaf surface is higher. Moreover, these culture methods are still being used as an alternative to other methods in contemporary microbial ecology.

\section{ACKNOWLEDGEMENT}

R.K.P. Yadav was supported by a grant from the State Scholarships Foundation (IKY), Greece. He acknowledges Tribhuvan University, Kathmandu for granting him study leave. This project was also supported by the General Secretariat for Research and Technology, Ministry of Development, Greece (01 ED 317).

\section{REFERENCES}

Aneja, K.R. 2003. Experiments in Microbiology, Plant Pathology and Biotechnology. New Age International (P) Ltd., New Delhi.

Berger, C.N., S.V. Sodha, R.K. Shaw, P.M. Griffin, D. Pink, P. Hand and G. Frankel. 2010. Fresh fruit and vegetables as vehicles for the transmission of human pathogens. Environ. Microbiol. 12(9):2385-2397.

Corpe, W.A. and S. Rheem. 1989. Ecology of the methylotrophic bacteria on leaving leaf surfaces. FEMS Microbiol. Ecol. 62:243-250.

de Jager, E.S., F.C. Wehner and L. Korsten. 2001. Microbial ecology of the mango phylloplane. Microb. Ecol. 42:201-207.

Garland, J.L., A.L. Mills and J.S. Young. 2001. Relative effectiveness of kinetic analysis vs single point readings for classifying environmental samples based on communitylevel physiological profiles (CLPP). Soil Biol. Biochem. 33:1059-1066.

Jacques, M.-A., L. Kinkel and C.E. Morris. 1995. Population sizes immigration and growth of epiphytic bacteria on leaves of different ages and position of field-grown endive (Cichorium endivia var. latifolia). Appl. Environ. Microbiol. 61:899-906.

Kinkel, L., M. Wilson and S.E. Lindow. 1995. Effects of scale on estimates of epiphytic 
bacterial populations. Microb. Ecol. 29:282297

Knief, C., A. Ramette, L. Frances, Alonso-Blanco C. and J.A. Vorholt. 2010. Site and plant species are important determinants of the Methylobacterium community composition in the plant phyllosphere. The ISME Jour. 4:719728.

Lambais, M.R., D.E. Crowley, J.C. Cury, R.C. Büll and R.R. Rodrigues. 2006. Bacterial diversity in tree canopies of Atlantic forest. Science 312:1917.

Leben, C. 1988. Relative humidity and the survival of epiphytic bacteria with buds and leaves of cucumber plants. Phytopathology 78:179-185.

Legard, D.E., M.P. McQuilken, J.M. Whipps, J.S. Fenlon, I.P. Fermor, I.P. Thompson, M.J. Bailey and J.M. Lynch. 1994. Studies of seasonal changes in the microbial populations on the phyllosphere of spring wheat as a prelude to the release of a genetically modified microorganism. Agr. Ecosyst. Environ. 50:87101.

Lindow, S.E., D.C. Arny and C.D. Upper. 1978. Distribution of ice nucleation-active bacteria on plants in nature. Appl. Environ. Microbiol. 36:831-838.

Lindow, S.E. and M.T. Brandl. 2003. Microbiology of the phyllosphere. Appl. Environ. Microbiol. 69:1875-1883.

Mansvelt, E.L. and M.J. Hattingh. 1987. Scanning electron microscopy of colonization of pear leaves by Pseudomonas syringae pv. syringae. Can. J. Bot. 65:2517-2522.

Mariano, R.L.R. and S.M. McCarter. 1993. Epiphytic survival of Pseudomonas viridiflava on tomato and selected weed species. Microb. Ecol. 26:47-58.
McCaig, A.E., E.A. Glover and J.I. Prosser. 1999. Molecular analysis of bacterial community structure and diversity in unimproved and improved grass pastures. Appl. Environ. Microbiol. 65:1721-1730.

Preston-Mafham, J., L. Boddy and P.F. Randerson. 2002. Analysis of microbial community functional diversity using sole-carbon source utilization profiles-a critique. FEMS Microbiol. Ecol. 42:1-14.

Rasche, F., E. Marco-Noales, H. Velvis, L.S. van Overbeek, M.M. Lopez, J.D. van Elsas and A. Sessitsch. 2006. Structural characteristics and plant-beneficial effects of bacteria colonizing the shoots of field grown conventional and genetically modified T4-lysozyme producing potatoes. Plant Soil 289:123-140.

Ritz, C. 2007. The plate debate: cultivable communities have no utility in contemporary environmental microbiology. FEMS Microbiol. Ecol. 60:358-362.

Torsvik, V., L. Ovreas and T.F. Thingstad. 2002. Prokaryotic diversity - magnitude, dynamics and controlling factors. Science 296:10641065.

Weller, D.M. and A.W. Saettler. 1980. Colonization and distribution of Xanthomonas phaseoli and X. phaseoli var. fuscans in fieldgrown navy beans. Phytopathology 70:500506.

Whipps, J.M., P. Hand, D.A.C. Pink and G.D. Bending. 2008. Human pathogens and the phyllosphere. Adv. Appl. Microbiol. 64:183221.

Yadav, R.K.P., A.M. Bosabalidis and D. Vokou. 2004a. Leaf structural features of Mediterranean perennial species: plasticity and life form specificity. J. Biol. Res. 2:21-34. 
Yadav, R.K.P., E.M. Papatheodorou, K. Yadav, R.K.P., K. Karamanoli and D. Vokou. Karamanoli, H.A. Constantinidou and D. 2005. Bacterial colonization of the Vokou. 2008. Abundance and diversity of the phyllosphere of Mediterranean perennial phyllosphere bacterial communities of species as influenced by leaf structural and Mediterranean perennial plants that differ in chemical features. Microb. Ecol. 50:185-196. leaf chemistry. Chemoecology 18:217-226.

Yadav, R.K.P., J.M. Halley, K. Karamanoli, H.-I. Constantinidou and D. Vokou. 2004. Bacterial populations on the leaves of Mediterranean plants: quantitative features and testing of distribution models. Environ. Exp. Bot. 52:63Yang, C-H., D.E. Crowley, J. Morneman and N.T. Keen. 2001. Microbial phyllosphere populations are more complex than previously realized. Proc. Nat. Acad. Sci. USA, 98:38893894.

77. 